\title{
Optimization of 3-Pyrimidin-4-yl-oxazolidin-2-ones as Allosteric and Mutant Specific Inhibitors of IDH1
}

\author{
Julian R. Levell, ${ }^{\dagger}{ }^{\dagger}$ Thomas Caferro, Gregg Chenail, Ina Dix, Julia Dooley, Brant Firestone, \\ Pascal D. Fortin, " John Giraldes," Ty Gould, Joseph D. Growney, Michael D. Jones, Raviraj Kulathila, \\ Fallon Lin, Gang Liu, Arne Mueller, Simon van der Plas, Kelly Slocum, Troy Smith, Remi Terranova, \\ B. Barry Touré, ${ }^{+}$Viraj Tyagi, Trixie Wagner, Xiaoling Xie, Ming Xu, ${ }^{\S}$ Fan S. Yang, Liping X. Zhou, ${ }^{\perp}$ \\ Raymond Pagliarini,* and Young Shin Cho*
}

Novartis Institutes for Biomedical Research, 250 Massachusetts Avenue, Cambridge, Massachusetts 02139, United States

Supporting Information

ABSTRACT: High throughput screening and subsequent hit validation identified 4-isopropyl-3-(2-((1-phenylethyl)amino)pyrimidin-4-yl)oxazolidin-2-one as a potent inhibitor of $\mathrm{IDH}_{1}{ }^{\mathrm{R} 132 \mathrm{H}}$. Synthesis of the four separate stereoisomers identified the $(S, S)$-diastereomer (IDH125, 1f) as the most potent isomer. This also showed reasonable cellular activity and excellent selectivity vs IDH $1^{\text {wt }}$. Initial structure-activity relationship exploration identified the key tolerances and potential for optimization. X-ray crystallography identified a functionally relevant allosteric binding site amenable to inhibitors, which can penetrate the blood-brain barrier, and aided rational optimization. Potency improvement and modulation of the physicochemical properties identified $(S, S)$-oxazolidinone IDH889 (5x) with good exposure and 2-HG inhibitory activity in a mutant IDH1 xenograft mouse model.

KEYWORDS: Mutant IDH1 inhibitor, allosteric inhibition, 2-HG, preclinical in vivo activity, 3-pyrimidin-4-yloxazolidin-2-one, chirality-defined potency

$\mathrm{H}$ otspot heterozygous mutations in human cytoplasmic isocitrate dehydrogenase 1 (IDH1) at $\operatorname{Arg}^{132}$ (R132*) have been identified in multiple cancer types, including acute myeloid leukemia (AML), glioma, chondrosarcoma, and cholangiocarcinoma. ${ }^{1}$ These mutations have been shown to confer a neomorphic catalytic activity to produce high levels of intracellular R-2-hydroxyglutarate (2-HG) and effect downstream epigenetic markers on DNA and proteins. ${ }^{2,3}$ Catalytic inhibitors ${ }^{4-10}$ of $\mathrm{IDH}^{\mathrm{R} 132} *$ have shown preclinical reduction of 2-HG levels in xenograft mouse models with mutant IDH1 tumors and have also shown preclinical tumor regression. ${ }^{4-7}$ Recent clinical trials in AML patients with a specific inhibitor of IDH1 has shown clinical benefit, confirming the causal link between this genetic mutation, the production of $2-\mathrm{HG}$, and cancer. ${ }^{11}$ Efforts herein focused on the identification of compounds that could potentially target all classes of mutantIDH1 tumors, including those in the brain.

The substrate-binding site of mutant IDH1 is highly polar as defined by the amino acids lining the pocket (Figure 1), in addition to the active-site magnesium ion and NADPH cofactor. This suggests a low probability of being able to optimize a compound for potent binding to this site while also fulfilling the criteria most conducive to crossing the bloodbrain barrier (BBB). ${ }^{12}$ It was decided to explore the identification of catalytic inhibitors with different mechanisms

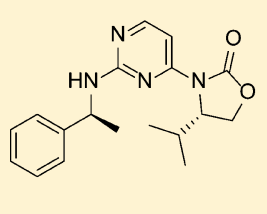

IDH125

$\mathrm{IDH}^{\mathrm{R} 132 \mathrm{H}} \mathrm{IC}_{50} 0.22 \mu \mathrm{M}$

Cell 2-HG IC ${ }_{50} 0.66 \mu \mathrm{M}$

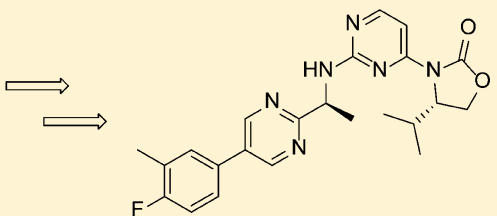

IDH889

$\mathrm{IDH}^{\mathrm{R} 132 \mathrm{H}} \mathrm{IC} \mathrm{C}_{50} 0.02 \mu \mathrm{M}$ Cell 2-HG IC ${ }_{50} 0.014 \mu \mathrm{M}$ 
Table 1. IDH1 ${ }^{\text {R132H }}$ Biochemical Activity of HTS Hits and Pure Resynthesized Diastereomers

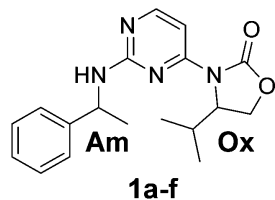

1a-f

\begin{tabular}{llcc} 
& $\begin{array}{c}\text { chirality at } \\
\text { amine }(\mathrm{Am})\end{array}$ & $\begin{array}{c}\text { chirality at } \\
\text { oxazolidinone }(\mathrm{Ox})\end{array}$ & $\begin{array}{c}\text { biochem. LCMS } \\
\mathrm{IC}_{50}(\mu \mathrm{M})\end{array}$ \\
1a & $R / S=1: 1$ & $S$ & 0.8 \\
1b & $R / S=1: 1$ & $R$ & 8.5 \\
1c & $R$ & $R$ & 19.7 \\
1d & $S$ & $R$ & 4.2 \\
1e & $R$ & $S$ & 4.6 \\
1f & $S$ & $S$ & 0.22 \\
(IDH125) & & & \\
\hline
\end{tabular}

although still significantly affected by the chirality at the oxazolidinone ( $\mathrm{Ox}$ ) (Table 1). The preference for the $S$-amine isomer was maintained throughout the structure-activity relationship (SAR) on the series, but the effect of $R$-chirality at the oxazolidinone was sometimes only marginal. As described elsewhere, ${ }^{13}$ compound 1f (IDH125) was validated with multiple biophysical methods, and this compound enabled considerable understanding of the rationale for selectivity and mechanism of action of this series. IDH125 was also confirmed as an essentially equipotent inhibitor of both the homodimer $\mathrm{IDH}^{\mathrm{R} 132 \mathrm{H}}\left(\mathrm{IC}_{50} 0.22 \mu \mathrm{M}\right)$ and $\mathrm{IDH1}^{\mathrm{R} 132 \mathrm{C}}\left(\mathrm{IC}_{50} 0.15 \mu \mathrm{M}\right)$ proteins and slightly less potent for the heterodimer $\mathrm{IDH} 1^{\mathrm{wt}}$ $\mathrm{IDH}^{\mathrm{R} 132 \mathrm{H}}\left(\mathrm{IC}_{50} 0.97 \mu \mathrm{M}\right)$ protein using NADPH fluorescence-based biochemical assay. ${ }^{13}$ The cancer-specific mutation of IDH1 and lack of activity of IDH125 against wild-type IDH1 up to $50 \mu \mathrm{M}$ presented an opportunity to develop an oncology drug with a high therapeutic index.

It was noted that IDH125 contains an aminopyrimidine core, which is a common motif in ATP-competitive kinase inhibitor scaffolds due to the structural similarity vs the purine nucleus of ATP. ${ }^{14}$ Therefore, initial thorough kinase profiling of IDH125 in an internal kinase profiling panel, as well as an external kinase profiling panel was carried out (Supporting Information). IDH125 demonstrated virtually no inhibitory activity across the entire kinome. This structural potential for off-target activity was monitored with internal and external kinase panels, but the lack of kinase activity was maintained throughout the series.

2,4-Dichloropyrimidine underwent selective 4-chloro substitution at room temperature, by reaction with the sodium salt of (S)-4-isopropyl-oxazolidin-2-one (Scheme 1). Subsequent displacement of the 2-chloro at $140{ }^{\circ} \mathrm{C}$ with $(S)$-1-phenylethan1-amine in DMSO gave $(S)$-4-isopropyl-3-(2- $(((S)-1$ phenylethyl)amino)pyrimidin-4-yl)oxazolidin-2-one (IDH125,

Scheme 1. Synthetic Scheme for 1f (IDH125)

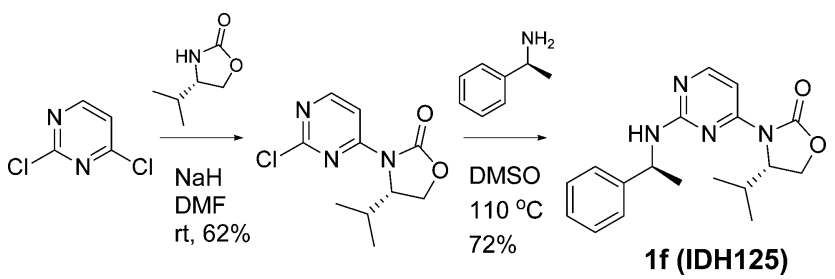

1f). The other diastereomers were accessed using the appropriate chiral building blocks.

SAR by archive using IDH125 as the probe structure was unsuccessful in identifying additional molecules in the Novartis compound library with submicromolar activity, highlighting that this substructure was somewhat unique. Initial analogues were targeted to explore the tolerance for modification and/or removal of different parts of the molecule (compounds $\mathbf{2 a - d}$, $\mathbf{3 a}-\mathbf{f}$, and $\mathbf{4 a}-\mathbf{d}$ in Supporting Information). Understanding of this initial SAR was clarified by the determination of the X-ray cocrystal structure of IDH125 in the homodimer of IDH1 $1^{\mathrm{R} 132 \mathrm{H}}$, which showed IDH125 binding into an allosteric site adjacent to the substrate binding site. ${ }^{13}$ Replacement of the nitrogen at the 3-position of the pyrimidine with a carbon, and either replacement of the 2-amino with an oxygen or $\mathrm{N}$-alkylation all resulted in loss of activity due to lack of backbone/ligand hydrogen bond donor-acceptor interactions to Leu ${ }^{120}$. Small substituents such as methyl on the 4- and 5-position of the pyrimidine were tolerated. The alpha-methyl of IDH125 binds into a small nook created by the backbone of $\mathrm{Arg}^{109}, \mathrm{Glu}^{110}$, and $\mathrm{Ile}^{128}$ as well as the side chains of $\mathrm{Ile}^{130}, \mathrm{Ser}^{278}$, and $\mathrm{Met}^{291}$ resulting in a good contact for a methyl group but limited tolerance for larger groups in this region. An unsubstituted oxazolidinone does not lead to the preferred hydrophobic collapse conformation required for binding, but there is tolerance for alternate oxazolidinone substituents beyond isopropyl. Interestingly, the bound structure of $\mathrm{IDH} \mathbf{1 2 5 ^ { 1 3 }}$ closely overlays with the small molecule X-ray structure, which suggests that hydrophobic collapse drives the molecule to preorder into the active binding conformation. The nature of the residues lining this allosteric pocket are also in stark contrast to those lining the substrate-binding site, and lend a more hydrophobic character to the pocket (Figure 2). This pocket has potential for potent binding of molecules, which may also be able to cross the BBB.

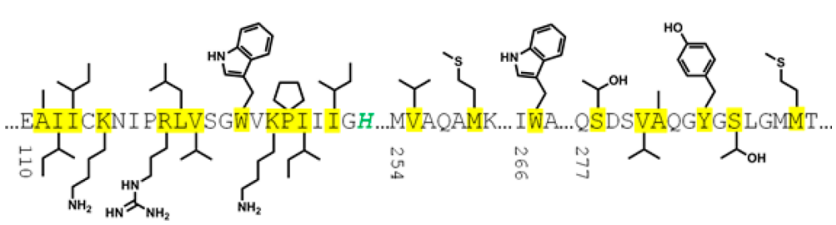

Figure 2. Sequence and side chain representation of the allosteric pocket for $\mathrm{IDH} 1^{\mathrm{R} 132 \mathrm{H}}$. Amino acids lining the pocket are highlighted in yellow, and mutation site $\mathrm{R} 132 \mathrm{H}$ is shown in green.

The limited ability to improve the potency with simple modifications to the oxazolidinone, alpha-methyl, or pyrimidine regions of IDH125 necessitated exploration of modifications to the phenyl group (Table 2). Saturation of the phenyl ring and simple substitutions appeared to be tolerated around the ring system (compounds $\mathbf{5 a}-\mathbf{m}$ ), although larger groups at the ortho position were less tolerated than the meta or para positions. In a similar fashion, 2-naphthyl $\mathbf{5 p}$ is also more potent than 1-naphthyl 5q. In the para-position, the fluoro and chloro groups appeared to give a slight boost in potency, but this was lost with the larger methoxy group. This could have been due to either a steric or electronic effect, but the electronwithdrawing $p$-cyano also showed a drop in potency, suggesting the loss of activity with electron-donating $p$-methoxy was not a wholly electronic effect. Despite the drop in activity for the $p$ methoxy and $p$-cyanophenyl, there was not the precipitous drop usually seen for a steric clash with an inflexible part of the 
Table 2. IDH1 ${ }^{\mathrm{R} 132 \mathrm{H}}$ Biochemical and HCT116-IDH1 ${ }^{\mathrm{R} 132 \mathrm{H}}$ Cellular Activity of Analogues Exploring Phenyl Substitution

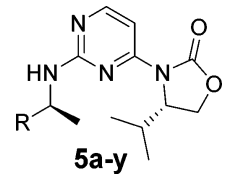

\begin{tabular}{|c|c|c|c|}
\hline & $\mathrm{R}$ & $\begin{array}{l}\text { Biochem } \\
\text { LCMS } \\
\mathrm{IC}_{50} / \mu \mathrm{M}\end{array}$ & $\begin{array}{l}\text { Cellular } \\
\mathrm{IC}_{50} / \mu \mathrm{M} \\
(2-\mathrm{HG})\end{array}$ \\
\hline $5 \mathbf{a}$ & cyclohexyl & 0.35 & 1.17 \\
\hline $5 \mathbf{b}$ & 2-fluorophenyl & 0.19 & 0.69 \\
\hline $5 c$ & 3-fluorophenyl & 0.25 & 0.42 \\
\hline 5d & 4-fluorophenyl & 0.15 & 0.35 \\
\hline $5 e$ & 3-chlorophenyl & 0.18 & 0.33 \\
\hline $5 f$ & 4-chlorophenyl & 0.13 & 0.16 \\
\hline $5 g$ & 3,4-dichlorophenyl & 0.097 & 0.09 \\
\hline $5 \mathbf{h}$ & 2-methoxyphenyl & 0.27 & 0.52 \\
\hline $5 \mathbf{i}$ & 3-methoxyphenyl & 0.13 & 0.43 \\
\hline $5 \mathbf{k}$ & 4-methoxyphenyl & 0.3 & 0.87 \\
\hline $5 \mathrm{~m}$ & $\begin{array}{l}\text { 3,4- } \\
\text { dimethoxyphenyl }\end{array}$ & 0.70 & 2.5 \\
\hline $5 n$ & 4-cyanophenyl & 0.54 & 1.34 \\
\hline $5 p$ & 1-naphthyl & 0.25 & 1.1 \\
\hline $5 q$ & 2-naphthyl & 0.094 & 0.16 \\
\hline $5 \mathbf{r}$ & p-biphenyl & 0.12 & 0.17 \\
\hline $\begin{array}{l}\text { 5s } \\
(\text { IDH662) }\end{array}$ & 4-phenoxyphenyl & 0.010 & 0.022 \\
\hline $5 t$ & $\begin{array}{l}\text { 5-chloro pyrimidin- } \\
2 \text {-yl }\end{array}$ & 2.1 & 7.9 \\
\hline $5 \mathbf{v}$ & & 0.081 & 0.2 \\
\hline $\mathbf{5} \mathbf{w}^{\dagger}$ & & 0.34 & 0.5 \\
\hline $\begin{array}{l}\mathbf{x} \\
(\text { IDH889) }\end{array}$ & & 0.02 & 0.014 \\
\hline
\end{tabular}

${ }^{\dagger}$ A 1:1 mixture of diastereomers at amine side chain.

protein. This suggested a low energy side chain or backbone movement of the protein in this region, which would accommodate larger side chains (i.e., for these intermediate sized groups the energy penalty for protein reorganization was not being compensated for by the interactions being made in the newly formed pocket). This hypothesis is supported by the potency seen with larger side chains such as $p$-biphenyl $\mathbf{5 r}$ and p-phenoxyphenyl 5s (IDH662). Interestingly, IDH662 also showed a significant boost in potency vs the $\mathrm{IDH}^{\mathrm{wt}}$ protein $\left(\mathrm{IDH}^{\mathrm{wt}} \mathrm{IC}_{50} 1.03 \mu \mathrm{M}\right)$, suggesting that the allosteric pocket is also accessible in the wt protein but is preferentially accessible in the R132 mutated protein. ${ }^{13}$

IDH662 was profiled vs a panel of in vitro assays and showed an overall excellent selectivity for the mutant protein. IDH662 showed potent cellular inhibition of $2-\mathrm{HG}$ production in the engineered HCT116-IDH1 ${ }^{\mathrm{R} 132 \mathrm{H}}$ cell line $\left(\mathrm{IC}_{50} 0.022 \mu \mathrm{M}\right)$ and inhibition of proliferation in the engineered MCF10A cell-line $\left(\mathrm{IC}_{50} 0.017 \mu \mathrm{M}\right)^{13}$ (cell lines available from Horizon Discovery Group plc $\left.^{15,16}\right)$. In comparison, IDH125 was considerably weaker in the HCT-116-IDH1 ${ }^{\mathrm{R} 132 \mathrm{H}}$ cell line $\left(\mathrm{IC}_{50} 0.66 \mu \mathrm{M}\right)$. Despite poor solubility $(<5 \mu \mathrm{M}$ at $\mathrm{pH} 6.8)$ and high in vitro clearance across species, in vivo exposure in mice (AUC 1.1 $\mu \mathrm{M} \cdot \mathrm{h}, C_{\max } 0.39 \mu \mathrm{M}$ at $10 \mathrm{mg} / \mathrm{kg}$ po, AUC $7.9 \mu \mathrm{M} \cdot \mathrm{h}, C_{\max } 2.5$ $\mu \mathrm{M}$ at $100 \mathrm{mg} / \mathrm{kg}$ po) was deemed sufficient to explore IDH662 in an in vivo pharmacodynamic (PD) study monitoring compound effects on 2-HG. However, at doses up to $600 \mathrm{mg} / \mathrm{kg}$ there was no significant alteration of 2-HG levels in xenograft tumor tissue in the HCT116-IDH1 ${ }^{\mathrm{R} 132 \mathrm{H}}$ model (data not shown). The estimated free compound concentration from the measured plasma pharmacokinetics $(\mathrm{PK})$ in this study was below the cellular $\mathrm{IC}_{50}$ for mutant IDH1, which suggested that the high plasma protein binding (>99\%) limited productive engagement of the target in vivo.

It was decided to explore whether in vivo modulation of 2HG inhibition was dependent on free-fraction of drug in the plasma. The high protein binding was likely contributing to a lower in vivo clearance than predicted from the in vitro microsomal assays, suggesting that lower intrinsic clearance would be needed in tandem with any increase of the free fraction in order to achieve high enough and effective exposures. In silico and in vivo metabolic studies highlighted the benzylamine as a key source of oxidative metabolic cleavage, so this was the focus of the next iteration of targets.

Heterocyclic replacements of the phenyl group should lower the oxidation potential of the benzylic carbon due to distribution of the local electron density through to the conjugated, and more electronegative, heteroatoms. Heterocycles would also increase the local polarity, and this may be less well tolerated in the binding sites of cytochrome P450 proteins, leading to reduced oxidative metabolism. This is supported by data from Ioannidis et al., who have shown excellent in vitro and in vivo $\mathrm{PK}$ properties with a structurally similar halopyrimidine benzylamine for a series of Janus kinase 2 (JAK2) inhibitors. ${ }^{17}$

The chemistry used to displace chloro from 2-chloro-4oxazolidinonyl pyrimidines with benzylamine derivatives was not efficient with less nucleophilic heterocyclic amines such as 1-(5-chloropyrimidin-2-yl)ethylamine. Therefore, the more reactive 2,4-difluoropyrimidine was used to enable the synthesis of the desired products via 2-fluoro-4-oxazolidinonylpyrimidine.

The comparison of chloropyrimidine (5t) to chlorophenyl (5f) shows a significant improvement in in vitro clearance in rat microsomes $\left(\mathrm{CL}_{\text {int }} 73 \mu \mathrm{L} / \mathrm{min} \cdot \mathrm{mg}\right.$ vs $\mathrm{CL}_{\text {int }}>900 \mu \mathrm{L} / \mathrm{min} \cdot \mathrm{mg}$ ), but this results in a 16-fold drop in biochemical activity and 50fold drop in cellular activity. A more moderate 8 to 10 -fold drop in activity is observed for the phenoxypyrimidine analogue $5 \mathrm{v}$ when compared to the analogous phenoxyphenyl IDH662. However, <3-fold drop in activity is seen for the phenylpyrimidine analogue (diastereomeric mixture $\mathbf{5 w}$ vs biphenyl 5r). Analogue $\mathbf{5 w}$ also shows an improved clearance in rat microsomes vs pyrimidine 5t (5w CL $\left.\mathrm{CL}_{\text {int }} 24 \mu \mathrm{L} / \mathrm{min} \mathrm{mg}\right)$, whereas phenoxypyrimidine $\mathbf{5 v}$ was significantly higher $\left(\mathrm{CL}_{\mathrm{int}}\right.$ $240 \mu \mathrm{L} / \mathrm{min} \mathrm{mg}$ ). Pyrimidine and para-biaryl motifs were maintained in subsequent analogues, leading to identification of IDH889 $\left[\mathrm{IDH}^{\mathrm{R} 132 \mathrm{C}} \mathrm{IC}_{50} 0.072 \mu \mathrm{M}, \mathrm{IDH}^{\mathrm{wt}} \mathrm{IC}_{50} 1.38 \mu \mathrm{M}\right]$.

X-ray crystallography of IDH889 (PDB 5TQH) in homodimer $\mathrm{IDH} 1^{\mathrm{R} 132 \mathrm{H}}$ is consistent with the structure of 
IDH125 (Figure 3)). ${ }^{13}$ The aminopyrimidine core moiety interacts with the backbone of $\mathrm{Ile}^{128}$ via a hydrogen bond

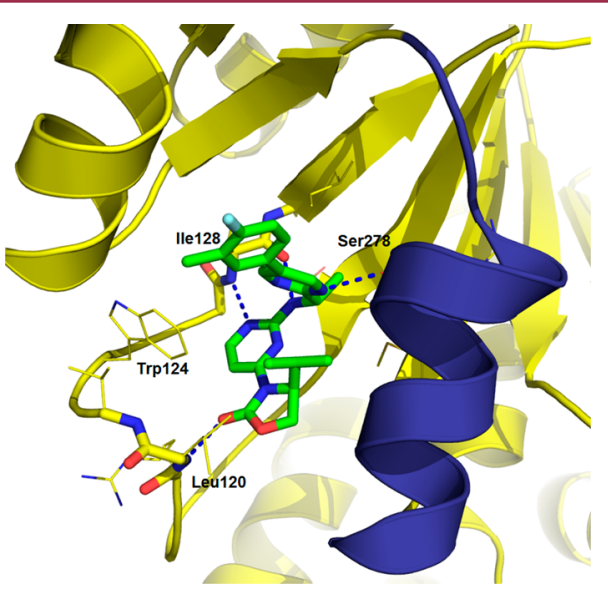

Figure 3. X-ray cocrystal structure of IDH889 in $\mathrm{IDH}^{\mathrm{R} 132 \mathrm{H}}$.

donor-acceptor pair, the carbonyl of the oxazolidinone forms a hydrogen bond interaction with Leu ${ }^{120}$, and the alpha-methyl fits into the methyl nook. The molecule is in a hydrophobic collapse conformation with the isopropyl in van der Waals contact with the pyrimidine of the amine side chain. In addition, a hydrogen bond is observed between the pyrimidine of the amine side chain and $\operatorname{Ser}^{278}$, and this specific interaction may be compensating for the expected increase in desolvation energy for a more polar ligand (vs the biphenyl 5r).

IDH889 demonstrates significantly improved plasma exposure in mice vs IDH662 (AUC $3.6 \mu \mathrm{M} \cdot \mathrm{h}, C_{\max } 1.7 \mu \mathrm{M}$ at 10 $\mathrm{mg} / \mathrm{kg}$; AUC $55.5 \mu \mathrm{M} \cdot \mathrm{h}, C_{\max } 14.2 \mu \mathrm{M}$ at $\left.100 \mathrm{mg} / \mathrm{kg}\right)$. This is coupled with an improved solubility $(39 \mu \mathrm{M}$ at $\mathrm{pH} 6.8)$ and measurable free fraction in mouse plasma ( $98 \%$ plasma protein binding), suggesting prolonged plasma concentration 20 -fold over the cellular $\mathrm{IC}_{50}$ could be achieved at a dose of $100 \mathrm{mg} / \mathrm{kg}$.

In the HCT116-IDH1 $1^{\mathrm{R} 132 \mathrm{H} \pm}$ xenograft model, IDH889 dosed orally at $200 \mathrm{mg} / \mathrm{kg}$ inhibits new 2 -HG production but does not eliminate 2-HG from IDH1 mutant tissues. Thus, given the high baseline tissue concentration of 2-HG, several hours are required to clear $2-\mathrm{HG}$ from the tissues. Peak reduction in tumor 2-HG levels after a single dose is observed $8-12 \mathrm{~h}$ postadministration. 2-HG levels begin to rebound as the free concentration of IDH889 drops below the in vitro cellular $\mathrm{IC}_{50}$ (Figure 4A). At $48 \mathrm{~h}$ post-treatment, 2-HG levels return to baseline. Sustained 2-HG inhibition greater than $24 \mathrm{~h}$ was achieved with BID (q12/12) administration of IDH889 for four doses (Figure 4B).

In a rat PK study to assess brain/plasma ratio, IDH889 demonstrates favorable distribution to the brain $(30 \mathrm{mg} / \mathrm{kg}$ po, 1.4 brain/blood ratio, $\mathrm{AUC}_{\text {brain }} 3117 \mathrm{nM} \cdot \mathrm{h}, \mathrm{AUC}_{\text {blood }} 2222 \mathrm{nM}$. h), albeit with a lower free fraction due to slightly higher rat brain protein binding (99.4\%) vs rat plasma protein binding. IDH889 also has excellent permeability and no efflux in the Caco-2 and human MDR1-MDCK cell lines, supporting the hypothesis that potent inhibition of mutant IDH1 function by binding at the allosteric binding site is compatible with brain penetration.

It was next tested whether the $2-\mathrm{HG}$ reduction was sufficient to alter DNA methylation, a phenotype closely linked to IDH1 mutation and 2-HG production. ${ }^{18,19}$ These studies were performed using Infinium Human Methylation 450 Bead
A

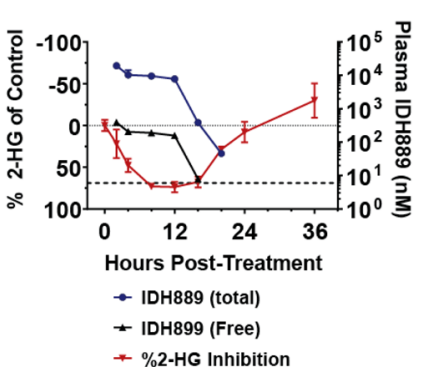

B

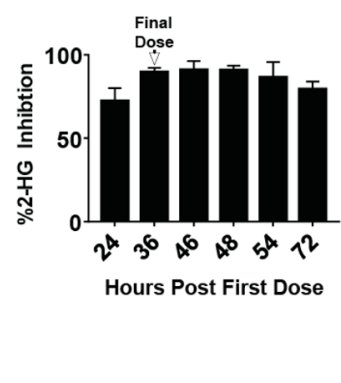

Figure 4. (A) Total and estimated free plasma IDH889 concentration (mean \pm SD) and percent inhibition of baseline 2-HG levels (mean \pm SEM) in HCT116-IDH1 ${ }^{\mathrm{R} 132}$ xenograft tumor tissue following a single $200 \mathrm{mg} / \mathrm{kg}$ dose (dotted line is zero \% inhibition, dashed line represents cellular $\mathrm{EC}_{50}$ ). (B) Percent inhibition (mean \pm SEM) of 2HG levels in tumor tissue following four doses of IDH889 at $25 \mathrm{mg} /$ $\mathrm{kg}$ po BID (q12/12).

Chip arrays (Supporting Information). Separately derived HCT116-IDH $1^{\mathrm{R} 132 \mathrm{H}}$ and HCT116-IDH1 ${ }^{\mathrm{R} 132 \mathrm{C}}$ cell line clones showed consistent changes in both DNA hyper- and hypomethylation vs their isogenic wild-type counterpart cell line, which were stable over time (Figure 5A). IDH889 caused time-dependent changes in these loci, with preferential hypomethylation of the loci in mutant cells that were originally hypermethylated in mutant vs wild-type cells. Importantly, IDH889 caused no consistent changes in DNA methylation in the wild-type control cell line, highlighting that the DNA methylation changes in the mutant clones were likely due to IDH1 mutation and 2-HG production. To validate these changes in vivo, tumor samples collected at necropsy from the $25 \mathrm{mg} / \mathrm{kg}$ BID study (Figure 4B) were evaluated to compare global methylation status vs tumors obtained from untreated control animals (3 samples/group), as well as parental wildtype (wt) HCT116 tumors. Figure 5B shows that a large number of sites in the genome were either hypermethylated (red) or hypomethylated (green) in IDH1 $1^{\mathrm{R} 132 \mathrm{H} \pm}$ mutant HCT 116 tumors vs wt control tumors. For the sites that were specifically altered in mutant tumors, IDH889 treatment caused both the hypermethylated and hypomethylated loci to trend toward reversion to their wt status (Figure $5 \mathrm{C}$ ). The sites not altered by $\mathrm{R} 132 \mathrm{H}$ mutation (Figure $5 \mathrm{~B}$, gray) showed only minor changes as a group upon IDH889 treatment (data not shown). Together, this data suggests that the level of 2-HG inhibition achieved in Figure 4B was sufficient to modulate mutant IDH1dependent DNA methylation changes in vivo.

In conclusion, a novel HTS hit was optimized for potency and PK properties to generate a tool molecule (IDH889) suitable for exploring the effect of inhibition of production of 2$\mathrm{HG}$ by $\mathrm{IDH} 1^{\mathrm{R} 132 \mathrm{H}}$ in preclinical in vitro and in vivo cancer models. IDH889 binds into an allosteric, induced-fit pocket in $\mathrm{IDH} 1^{\mathrm{R} 132 \mathrm{H}}$, has good overall selectivity vs the wt protein, and inhibits both the $\mathrm{IDH} 1^{\mathrm{R} 132 \mathrm{H}}$ and $\mathrm{IDH} 1^{\mathrm{R} 132 \mathrm{C}}$ mutants, suggesting broad utility across the various known R132* mutations. Oral dosing of IDH889 in a murine IDH1 mutant tumor xenograft model shows robust reduction of tumor derived $2-\mathrm{HG}$, a PD biomarker of mutant-IDH $1^{\mathrm{R} 132} *$ activity. In addition to the potential treatment of $\mathrm{AML}$, chondrosarcoma, cholangiocarcinoma, and other forms of mutant-IDH1 driven cancers, IDH889 demonstrates brain penetrant exposure. This suggests potential utility in preclinical orthotopic tumor models, as well as potential for the series 


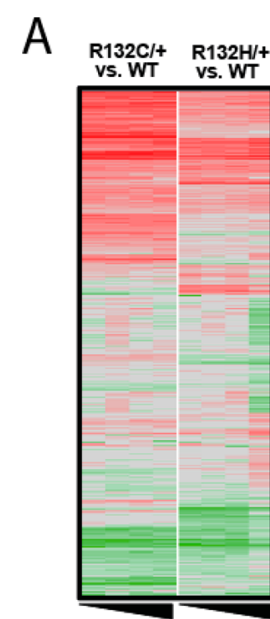

Days

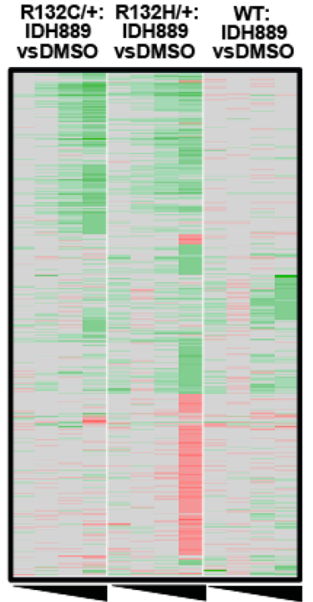

Days

B

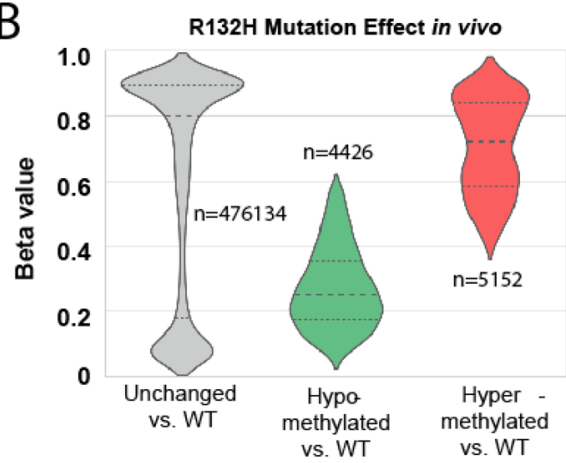

C

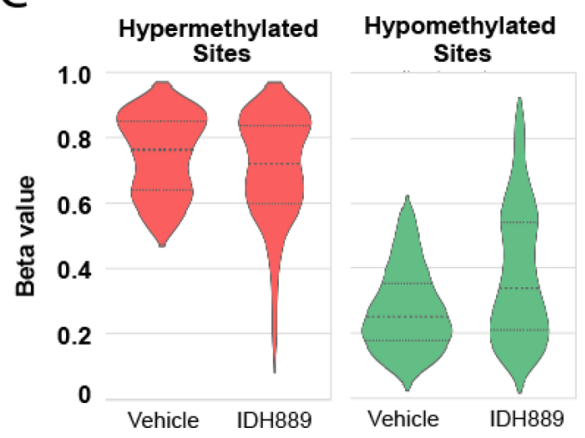

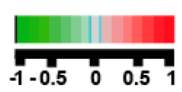

Figure 5. (A) In vitro DNA methylation changes upon IDH889 treatment in the indicated HCT116 cell clones. Rows represent individual sites in the genome, and columns within each cluster represent time points (days 3, 7, 14, and 28). Green shading indicates hypomethylation, and red shading indicates hypermethylation, delta values as described in Supporting Information. (B) Violin plots showing in vivo DNA methylation changes in $\mathrm{IDH}^{\mathrm{R} 132 \mathrm{H} /+}$ mutant vs wild-type HCT116 xenograft tumors. $Y$ axis level of methylation for each site $(1=$ methylated, $0=$ unmethylated: beta values, as described in Supporting Information), $n=$ number of sites within each group, large dashed line indicates median beta value, and smaller dashed lines indicate 75th (top) and 25th (bottom) percentiles. (C) Violin plot as in panel B for $\mathrm{IDH}^{\mathrm{R} 132 \mathrm{H}}$ mutant tumors after treatment with IDH889 (tumors from Figure 4B).

to be optimizable for treating patients with IDH1 mutant brain cancers.

\section{ASSOCIATED CONTENT}

\section{Supporting Information}

The Supporting Information is available free of charge on the ACS Publications website at DOI: 10.1021/acsmedchemlett.6b00334.

Synthetic procedures, analytical data, assay protocols, SAR of compounds $\mathbf{2 a - d}, \mathbf{3 a}-\mathbf{f}$, and $\mathbf{4 a - d}$, small molecule X-ray data of IDH125 and 1e, kinase profiling of IDH125, assay protocols, $\mathrm{PK}$ and $\mathrm{PK} / \mathrm{PD}$ study protocols (PDF)

\section{AUTHOR INFORMATION}

\section{Corresponding Authors}

*E-mail: raymond.pagliarini@novartis.com.

*E-mail: youngshin.cho@novartis.com.

ORCID ${ }^{\circ}$

Julian R. Levell: 0000-0002-6171-3819

\section{Present Addresses}

$\dagger$ (J.R.L.) Constellation Pharmaceuticals, 215 First Street, Suite 200, Cambridge, Massachusetts 02142, United States.

$\ddagger$ (P.D.F. and B.B.T.) Relay Therapeutics, 215 First Street, Suite 300, Cambridge, Massachusetts 02142, United States.

§(M.X.) Dupont, 1007 Market St. Wilmington, Delaware 19898, United States.

"(J.G.) National Cancer Institute, 9609 Medical Center Dr., Rockville, Maryland 20850, United States.

${ }^{\perp}$ (L.X.Z.) Ipsen Bioscience, Inc., 650 East Kendall Street, Cambridge, Massachusetts 02142, United States.

\#(B.F.) Surface Oncology, 215 First Street, Suite 400-S, Cambridge, Massachusetts 02142, United States.

\section{Notes}

The authors declare no competing financial interest.

\section{ACKNOWLEDGMENTS}

The authors would like to thank Thomas Smith, Kimberley Yue, and Daniel Baird for screen optimization and execution; Kara Herlihy, Tami Hood, and Suzanne Zhu for their help with the development of the in vitro activity assays; and Bill Sellers, Markus Warmuth, Karin Briner, Juerg Zimmerman, Tim Ramsey, and Travis Stams for project support.

\section{REFERENCES}

(1) Cairns, R. A.; Mak, T. W. Oncogenic isocitrate dehydrogenase mutations: mechanisms, models, and clinical opportunities. Cancer Discovery 2013, 3, 730-41.

(2) Dang, L.; White, D. W.; Gross, S.; Bennett, B. D.; Bittinger, M. A.; Driggers, E. M.; Fantin, V. R.; Jang, H. G.; Jin, S.; Keenan, M. C.; Marks, K. M.; Prins, R. M.; Ward, P. S.; Yen, K. E.; Liau, L. M.; Rabinowitz, J. D.; Cantley, L. C.; Thompson, C. B.; Vander Heiden, M. G.; Su, S. M. Cancer-associated IDH1 mutations produce 2hydroxyglutarate. Nature 2009, 462, 739-44.

(3) Losman, J. A.; Kaelin, W. G., Jr. What a difference a hydroxyl makes: mutant IDH, (R)-2-hydroxyglutarate, and cancer. Genes Dev. 2013, 27, 836-52.

(4) Popovici-Muller, J.; Saunders, J. O.; Salituro, F. G.; Travins, J. M.; Yan, S.; Zhao, F.; Gross, S.; Dang, L.; Yen, K. E.; Yang, H.; Straley, K. S.; Jin, S.; Kunii, K.; Fantin, V. R.; Zhang, S.; Pan, O.; Shi, D.; Biller, S. A.; Su, S. M. Discovery of the first potent inhibitors of mutant IDH1 that lower tumor 2-HG in vivo. ACS Med. Chem. Lett. 2012, 3, 850-5.

(5) Brooks, E.; Wu, X.; Hanel, A.; Nguyen, S.; Wang, J.; Zhang, J.; Harrison, A.; Zhang, W. Identification and characterization of smallmolecule inhibitors of the $\mathrm{R} 132 \mathrm{H} / \mathrm{R} 132 \mathrm{H}$ mutant isocitrate 
dehydrogenase 1 homodimer and $\mathrm{R} 132 \mathrm{H} /$ wild-type heterodimer. J. Biomol. Screening 2014, 19, 1193-1200.

(6) Deng, G.; Shen, J.; Yin, M.; McManus, J.; Mathieu, M.; Gee, P.; He, T.; Shi, C.; Bedel, O.; McLean, L. R.; Le-Strat, F.; Zhang, Y.; Marquette, J. P.; Gao, Q.; Zhang, B.; Rak, A.; Hoffmann, D.; Rooney, E.; Vassort, A.; Englaro, W.; Li, Y.; Patel, V.; Adrian, F.; Gross, S.; Wiederschain, D.; Cheng, H.; Licht, S. Selective inhibition of mutant isocitrate dehydrogenase 1 (IDH1) via disruption of a metal binding network by an allosteric small molecule. J. Biol. Chem. 2015, 290, 76274.

(7) Okoye-Okafor, U. C.; Bartholdy, B.; Cartier, J.; Gao, E. N.; Pietrak, B.; Rendina, A. R.; Rominger, C.; Quinn, C.; Smallwood, A.; Wiggall, K. J.; Reif, A. J.; Schmidt, S. J.; Qi, H.; Zhao, H.; Joberty, G.; Faelth-Savitski, M.; Bantscheff, M.; Drewes, G.; Duraiswami, C.; Brady, P.; Groy, A.; Narayanagari, S. R.; Antony-Debre, I.; Mitchell, K.; Wang, H. R.; Kao, Y. R.; Christopeit, M.; Carvajal, L.; Barreyro, L.; Paietta, E.; Makishima, H.; Will, B.; Concha, N.; Adams, N. D.; Schwartz, B.; McCabe, M. T.; Maciejewski, J.; Verma, A.; Steidl, U. New IDH1 mutant inhibitors for treatment of acute myeloid leukemia. Nat. Chem. Biol. 2015, 11, 878-86.

(8) Rohle, D.; Popovici-Muller, J.; Palaskas, N.; Turcan, S.; Grommes, C.; Campos, C.; Tsoi, J.; Clark, O.; Oldrini, B.; Komisopoulou, E.; Kunii, K.; Pedraza, A.; Schalm, S.; Silverman, L.; Miller, A.; Wang, F.; Yang, H.; Chen, Y.; Kernytsky, A.; Rosenblum, M. K.; Liu, W.; Biller, S. A.; Su, S. M.; Brennan, C. W.; Chan, T. A.; Graeber, T. G.; Yen, K. E.; Mellinghoff, I. K. An inhibitor of mutant IDH1 delays growth and promotes differentiation of glioma cells. Science 2013, 340 (6132), 626-630.

(9) Zheng, B.; Yao, Y.; Liu, Z.; Deng, L.; Anglin, J. L.; Jiang, H.; Prasad, B. V. V.; Song, Y. Crystallographic investigation and selective inhibition of mutant isocitrate dehydrogenase. ACS Med. Chem. Lett. 2013, 4, 542.

(10) Liu, Z.; Yao, Y.; Kogiso, M.; Zheng, B.; Deng, L.; Qiu, J. J.; Dong, S.; Lv, H.; Gallo, J. M.; Li, X.-N.; Song, Y. Inhibition of cancerassociated mutant isocitrate dehydrogenases: synthesis, structureactivity relationship, and selective antitumor activity. J. Med. Chem. 2014, 57, 8307-8318.

(11) Fan, B.; Le, K.; Manyak, E.; Liu, H.; Prahl, M.; Bowden, C. J.; Biller, S.; Agresta, S.; Yang, H. Longitudinal pharmacokinetic/ pharmacodynamic profile of AG-120, a potent inhibitor of the IDH1 mutant protein, in a phase 1 study of IDH1-mutant advanced hematologic malignancies. Blood 2015, 126, 1310.

(12) Rankovic, Z. CNS Drug Design: Balancing physicochemical properties for optimal brain exposure. J. Med. Chem. 2015, 58, 2584.

(13) Xie, X.; Capka, V.; Chen, J.; Chenail, G.; Cho, Y. S.; Dooley, J.; Farsidjani, A.; Fortin, P. D.; Kohl, D.; Kulathila, R.; Lin, F.; McKay, D.; Sage, D.; van der Plas, S.; Wright, K.; Xu, M.; Yin, H.; Levell, J.; Pagliarini, R. A. Allosteric mutant IDH1 inhibitors reveal mechanisms for IDH1 mutant and isoform selectivity. Structure 2016, submitted.

(14) Wu, P.; Nielsen, T. E.; Clausen, M. H. Small-molecule kinase inhibitors: an analysis of FDA-approved drugs. Drug Discovery Today 2016, 21 (1), 5.

(15) Horizon Discovery Group plc. Human IDH1(R132H/+) HCT116 cell line: HD 104-013; Human IDH1(R132H/+) MCF10A cell line: HD 101-013. www.horizondiscovery.com.

(16) http://www.ncbi.nlm.nih.gov/pubmed/23038259.

(17) Ioannidis, S.; Lamb, M. L.; Wang, T.; Almeida, L.; Block, M. H.; Davies, A. M.; Peng, B.; Su, M.; Zhang, H.-J.; Hoffmann, E.; Rivard, C.; Green, I.; Howard, T.; Pollard, H.; Read, J.; Alimzhanov, M.; Bebernitz, G.; Bell, K.; Ye, M.; Huszar, D.; Zinda, M. Discovery of 5chloro- $\mathrm{N}^{2}$-[(1S)-1-(5-fluoropyrimidin-2-yl)ethyl]- $\mathrm{N}^{4}$-(5-methyl-1Hpyrazol-3-yl)-pyrimidine-2,4-diamine (AZD1480) as a novel inhibitor of the JAK/STAT pathway. J. Med. Chem. 2011, 54, 262.

(18) Turcan, S.; Rohle, D.; Goenka, A.; Walsh, L. A.; Fang, F.; Yilmaz, E.; Campos, C.; Fabius, A. W.; Lu, C.; Ward, P. S.; Thompson, C. B.; Kaufman, A.; Guryanova, O.; Levine, R.; Heguy, A.; Viale, A.; Morris, L. G.; Huse, J. T.; Mellinghoff, I. K.; Chan, T. A. IDH1 mutation is sufficient to establish the glioma hypermethylator phenotype. Nature 2012, 483, 479.
(19) Duncan, C. G.; Barwick, B. G.; Jin, G.; Rago, C.; KapoorVazirani, P.; Powell, D. R.; chi, J. T.; Bigner, D. D.; Vertino, P. M.; Yan, H. A heterozygous IDH1R132H/WT mutation induces genomewide alterations in DNA methylation. Genome Res. 2012, 22, 2339. 